\title{
ACHADOS BUCAIS EM PACIENTES USUÁRIOS DE CRACK - RELATO DE CASOS
}

Helena Laskawski KLEMBA, Isabele Viechniewski SEEMULLER, Guilherme CORDEIRO, Rodrigo Hideki YOSHIYASU, Antonio Adilson Soares de LIMA

O crack é uma droga ilícita derivada da cocaína e o seu uso freqüente causa uma rápida dependência química. Atualmente, o consumo desta droga tornou-se muito comum no Brasil e é considerado um problema de saúde pública. O efeito imediato do crack é uma intensa euforia e se usado freqüentemente pode causar parada cardíaca, hemorragia pulmonar, pneumonia, infarto de músculos e da pele, úlceras no trato gastrointestinal, lesões bucais e de orofaringe. O seguinte trabalho visa apresentar dois relatos de casos de alguns achados bucais relacionados ao consumo desta droga. Nos dois casos, os pacientes são homens, dependentes químicos do crack, internados no Instituto de Pesquisa e Tratamento do Alcoolismo para tratamento de desintoxicação. No caso 1 , o paciente apresentava o dente 11 fraturado e uma hiperceratose reacional no vermelhão do lábio inferior causados pelo trauma contínuo do cachimbo nestas regiões. No paciente do caso 2 foi observada uma tatuagem na mucosa do lábio inferior, agenesia e a permanência de dentes decíduos. O cirurgião dentista deve estar atento a alguns achados bucais que possam estar relacionados ao consumo de drogas ilícitas e, com isso, estar preparado para atender este tipo de paciente, cada vez mais comum nos consultórios odontológicos.

Palavras chave: Cocaína Crack; Boca; Anormalidades da Boca; Cárie Dentária. 